\title{
Research on Status and Countermeasures of Industrial Energy Consumption and Carbon Emissions in Beijing
}

\author{
Y.Y.Li \& J.Wang \\ Institute of Recycling Economy, Beijing University of Technology, Beijing, China
}

\begin{abstract}
Industry is the main aero of the city's energy saving and emission reduction. Currently, the industrial energy consumption and carbon emission has a high proportion of the whole energy consumption and carbon emission in Beijing. It will have great practical significances to research the characteristics and major factors of Beijing's industrial energy consumption and carbon emissions. Basing on the statistical data collected, the existing problems and deficiencies of industrial energy consumption in Beijing were analyzed. Then the energy consumption and carbon dioxide emissions in next decade were predicted using GM (1.1) model and the exponential model. Based on this, the policy recommendations of the industries low-carbon development which in line with the functional orientation in capital.

KEYWORD: Beijing; Industrial energy consumption; Carbon emissions; Low-carbon development
\end{abstract}

\section{INSTRUCTIONS}

With the development of the capital economy in recent years, Beijing has made a great progress on the way to constructing a world city. The results of Beaver-stock's relative empirical indicated that the capital city has become a member of world urban system: the advantages of science and technology areas in the capital has been prominent and the influence of political, economic and cultural has increased. However, there is still a certain gap for Beijing compared with the developed cities in high levels [1-2]. Therefore, it requires to further optimize the industrial structure and energy consumption's structure of Beijing [3-4].

\section{SITUATION ANALYSIS}

\subsection{Analysis of industrial development}

Figure 1 showed that the added value of above-scale of industries of Beijing overall show an upward trend accompanied by a slight decline in 2008. Among them, the added value of heavy industries takes a large proportion of the added value of abovescale of industries which 2000 is $68.42 \%, 79.1 \%$ in $2005,79.7 \%$ in 2010 and $77.54 \%$ in 2012.The large industries of the added value of above-scale of industries of Beijing include automobile manufacturing; electricity, heat production and supply industry; computer, communications and other electronic equipment manufacturing; pharmaceutical manufacturing; petroleum processing, coking and nuclear fuel processing industry which accounted for $18.66 \%, 17.67 \%, 8.03 \%, 7.32 \%$, $4.16 \%$ respectively. The proportion of the five industries is 55.85 percent.

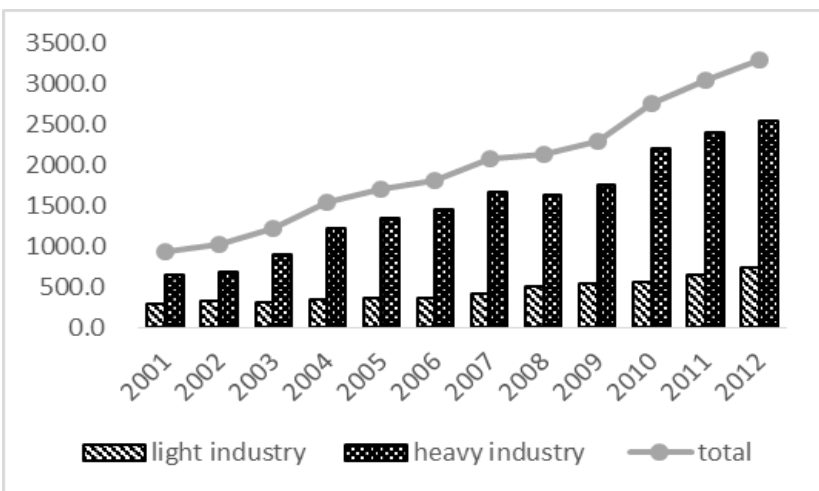

Figure 1. The added value of above-scale of light and heavy industries of Beijing during 2000-2012 (one hundred million yuan)

\subsection{Analysis of the industrial energy consumption and carbon emissions}

Table 1 showed that the industrial energy consumption in Beijing had a gradual upward trend from 2001 to 2007. It had an increase of 1.68 million tons of standard coal in 2010 compared to 2009, which mainly caused by the significant increase in the black metal mining industry. After then it began to decline, with 22.76 million tons of standard 
coal in 2012. Although the figure shows the trend of industrial energy consumption in Beijing is not obvious, but industrial energy consumption accounts for the total energy consumption in Beijing declined steadily decreased from $54.1 \%$ in 2001 to $31.7 \%$ in 2012. At the same time the carbon emissions of the industry increased first and then decreased.

Tab. 1 The industrial energy consumption (ten thousand tons of standard coal) and carbon emissions of Beijing during 20002012

\begin{tabular}{|c|l|l|l|l|l|l|}
\hline Years & 2001 & 2002 & 2003 & 2004 & 2005 & 2006 \\
\hline Energy consumption & 2288 & 2325 & 2380 & 2550 & 2599 & 2670 \\
\hline Carbon emissions & 5628 & 5721 & 5855 & 6274 & 6394 & 6568 \\
\hline Years & 2007 & 2008 & 2009 & 2010 & 2011 & 2012 \\
\hline energy consumption & 2685 & 2431 & 2392 & 2560 & 2330 & 2276 \\
\hline carbon emissions & 6605 & 5980 & 5885 & 6297 & 5731 & 5598 \\
\hline
\end{tabular}

\subsection{Analysis of industrial energy intensity and carbon intensity}

Table 2 showed that the energy intensity in Beijing had a gradual decline trend from 2001 to 2012 with $11.04 \%$ average annual rate of descend. The carbon intensity decreased from6.05 million/tons in 2001 to1.76 million/tons 2012 with $11.09 \%$ average annual rate of descend.

Tab. 2 The energy intensity (tons of standard coal) and carbon intensity (tons / million) of Beijing during 2000-2012 are shown in table 2 .

\begin{tabular}{|c|l|l|l|l|l|l|}
\hline Years & 2001 & 2002 & 2003 & 2004 & 2005 & 2006 \\
\hline Energy intensity & 2.46 & 2.32 & 2.11 & 1.90 & 1.52 & 1.43 \\
\hline Carbon intensity & 6.05 & 5.70 & 5.20 & 4.67 & 3.75 & 3.52 \\
\hline Years & 2007 & 2008 & 2009 & 2010 & 2011 & 2012 \\
\hline Energy intensity & 1.27 & 1.15 & 1.04 & 0.93 & 0.78 & 0.72 \\
\hline Carbon intensity & 3.13 & 2.82 & 2.55 & 2.28 & 1.93 & 1.76 \\
\hline
\end{tabular}

\section{PREDICTION OF INDUSTRIAL ENERGY CONSUMPTION}

According to status quo of carbon emissions of industrial energy consumption in Beijing during 2000-2012, predict industrial energy consumption, carbon emissions, energy intensity and carbon intensity in next decade by GM $(1,1)$ model.

Energy consumption: $y_{1}(t)=2888.3 e^{-0.021 t}(t=1,2, \ldots)$

Carbon emissions: $\quad y_{2}(t)=6549.9-32.5 \mathrm{t}-10.6 \mathrm{t}^{2}(t=1,2, \ldots)$

Energy intensity: $y_{3}(t)=-12.6585\left(1-e^{0.1231}\right) e^{-0.1231 t}(t=1,2, \ldots)$

Carbon intensity: $y_{4}(t)=-31.14\left(1-e^{0.1231}\right) e^{-0.1231 t}(t=1,2, \ldots)$
Since $\mathrm{F}$ values of industrial energy consumption and carbon emissions statistic were more than 0 , accept the null hypothesis (H0). The prediction models were through testing for linear relationship were established remarkably. The posterior error ratio of first industry, third industry and the city's total is less than 0.35 and small error probability is greater than 0.95 , which illustrates the high precision of three models can be used to predict.

Tab. 3 Index prediction of industrial energy consumption in Beijing during 2013-2020

\begin{tabular}{|l|l|l|l|l|}
\hline \multicolumn{1}{|c|}{ Years } & 2013 & 2014 & 2015 & 2016 \\
\hline $\begin{array}{l}\text { Energy consumption } \\
\text { (million tons of standard coal) }\end{array}$ & 2263 & 2216 & 2170 & 2124 \\
\hline Carbon emissions (million tons) & 5399 & 5165 & 4910 & 4634 \\
\hline $\begin{array}{l}\text { Energy intensity (tons of } \\
\text { standard coal) }\end{array}$ & 0.619 & 0.548 & 0.484 & 0.428 \\
\hline Carbon intensity (tons / million) & 1.524 & 1.347 & 1.191 & 1.053 \\
\hline Years & 2017 & 2018 & 2019 & 2020 \\
\hline $\begin{array}{l}\text { Energy consumption (million } \\
\text { tons of standard coal) }\end{array}$ & 2080 & 2037 & 1994 & 1953 \\
\hline Carbon emissions (million tons) & 4336 & 4017 & 3677 & 3316 \\
\hline $\begin{array}{l}\text { Energy intensity (tons of } \\
\text { standard coal) }\end{array}$ & 0.379 & 0.335 & 0.296 & 0.262 \\
\hline Carbon intensity (tons / million) & 0.931 & 0.823 & 0.728 & 0.644 \\
\hline
\end{tabular}

Table 3 shows decline trends of the indicators above. The industrial energy consumption decreased from 22.63 million tons of standard coal in 2013 to 19.53 million tons of standard coal in 2022 with $2.09 \%$ average annual rate of descend. As the same, carbon emissions decreased from 53.99 million tons in 2013 to 33.16 million tons in 2022. Average annual rate of energy intensity is $11.56 \%$ and carbon intensity is $11.58 \%$.

\section{PROBLEMS OF CARBON EMISSIONS IN BEIJING}

Currently, it has been facing with the following four outstanding issues:

\subsection{The industrial structure is unreasonable}

In the process of industrial development, reducing the carbon emissions in high pollution, high energy consumption industries can effectively achieve a low-carbon industrial development of Capital. In 2012, the energy consumption of tertiary industry and living consumption accounted for $65 \%$ of the city's total, indicating that the focus of capital's consumption has shifted. However, the structure of the industrial sector should be further optimized. The main Manufacture's energy consumption (including 
Processing of Petroleum, Coking of Nuclear Fuel, Non-Metallic Mineral Products and Chemical Materials and Chemical Products) still has a high proportion of the total industrial energy consumption. The marginal costs of promoting industrial energy saving in traditional way is gradually increasing, which make a narrow space of energy conservation.

\subsection{Heavy industrialization was significantly more than that of the developed countries}

Compared with the world's developed countries, it is still shows an extensive and epitaxial features of the development pattern of heavy industrialization in capital. There was a negative impact on the environment caused by significantly increasing of resources and energy consumption. In 2000, the output value of heavy industry industrial accounted for more than $70 \%$ of the whole industry and nearly closed to $85 \%$ in 2012 which showed a high growth momentum. The automotive manufacturing, electricity, petroleum processing, coking and nuclear fuel processing industry and other heavy industry were the main engine of the economy growth in Beijing.

\subsection{Energy consumption is dominated by coal}

Beijing uses much more coal than natural gas and the coal accounts for about $47.1 \%$ of its total energy consumption, so the proportion of high-quality energy is believed to be small. In contrast, developed countries use much more oil and natural gas, which consume a few coal. For example, natural gas accounted for $45.2 \%$ of the total energy consumed in London, oil accounted for $50.3 \%$ in New York and oil accounted for $38.5 \%$ in Tokyo. In recent years, positive measures aimed at controlling the quantities of coal were taken in Beijing. Nevertheless, the proportion of coal accounts for energy in Beijing is still large. The proportion of natural gas, hydro power and other clean energy sources, although shows rapid growth trend, but the proportion of the total energy is still small.

\subsection{High proportion of industrial carbon emissions}

The carbon emissions in world's developed cities such as New York, London, and Tokyo mainly came from the construction, transportation and living consumption. On the contrary, it mainly came from the industrial energy consumption in Beijing. The proportion of industrial carbon emissions in Beijing were 5.08, 3.94, 6.75 times than that in Tokyo, London, New York. This phenomenon are mainly caused by two reasons. On the one hand, the economic scale of Beijing is comparatively smaller than New York, London, Tokyo and other cities. On the other hand, the development stage of capital is quite different from other countries, which still have gaps in industrial structure, technological level, urbanization and environmental awareness.

\section{SUGGESTIONS OF INDUSTRIAL ENERGY CONSUMPTION AND LOW CARBON}

According to the characteristics of the carbon emissions of industrial energy consumption in capital, put forward the following countermeasures and Suggestions for the low carbon development:

\subsection{Promote the optimization of industrial structure and drive the development of industrial low- carbon}

In order to promote the industrial low carbon development in Beijing, it must adopt corresponding measures to optimize the industrial structure. The first is to eliminate the capacity pollutants products. To promote the adjustment and exit of the high energy consumption and high emission industries, it should make corresponding adjustment or exit guide catalog for the industry that does not meet the low carbon economic development. Control the total amount of large energy consumption and high carbon industry with compressing industry energy consumption by reorganization or merger, etc. 8 . The second is to further promote the transformation and exit of the four big thermal power plants. Thirdly, it should make full use of new energy and low carbon technology of energy conservation and environmental protection. Audit the rationality of the layout, equipment level and environmental protection facilities of the small pollution enterprises, then conduct a comprehensive plan to promote transformation of the traditional industrial enterprises.

\subsection{Adjust the energy structure and improve the proportion of high quality energy}

Green manufacturing is one of the construction index system in "Green Beijing". The capital should vigorously develop clean energy, and improve the proportion of high quality energy. Combined with current situation of resources endowment of the capital, it should constantly promote the development of new energy and renewable energy, and actively introduce the external clean energy to build a clean energy system with electricity, natural gas, solar energy, etc. First, the implementation of control of amount of the coal consumption, raise the proportion of high quality energy, and improve the efficiency of power distribution. Thus build a multivariate, safety, and low carbon energy supply system. Second, improve the efficiency of energy 
using .Vigorously promote low carbon production technology of energy conservation and environmental protection, and actively encourage the ladder-type of energy utilization technology 9. Finally, promote the clean energy of enterprise production. Adjust the enterprises who have underutilized of the energy using by transforming the clean energy. At last, push forward the coal reduction of urban and suburb areas in Beijing.

\subsection{Adhere to the system innovation and accelerate the mechanism construction of the low carbon development}

System innovation is the theoretical cornerstone to promote the development of low carbon city. Only fundamentally eliminate Institutional barriers which is disadvantageous to the low carbon development, can effectively promote the development of the industrial structure. Therefore, Beijing should be guided by the construction of low carbon economy. By the comprehensive consideration of economic benefit and environment benefit, reflect on the traditional pattern of development with high energy consumption and accelerate the mechanism construction of low carbon development. Although, Beijing has issued related laws and regulations to promote the development of low-carbon economy depending on its own situation, they are remained to be improved in the structure. It is lack of basic laws and regulations in the field of energy consumption in Beijing, especially in the oil and gas fields 10 . Beijing should perfect the legislation on energy law, promote the energy management system and formulate the evaluation of energy-saving target and administrative accountability system.

\subsection{Innovate Low carbon energy saving technology and practice clean production}

Conducting low-carbon energy saving technology is a major driving force for the development of lowcarbon economy. On the one hand, it need further improve the efficiency of thermodynamic. Reasonable to improve energy efficiency to achieve the purpose of improving the cost-effectiveness by using cogenerating heat and power. On the other hand, develop the carbon capture, utilization and storage technologies (CCUS), actively organize and research the oil, geothermal stimulation and relevant technical means by using carbon dioxide. Therefore, Beijing should make full use of existing community resources and establish effective incentive and restraint mechanisms measures to accelerate the development of low-carbon technologies. Meanwhile, Beijing should actively expand the breadth and depth of cleaner production, strengthen audit work of industrial cleaner production to format General Rule of clean production evaluation standards. Finally, organize audit program of clean production to the high energy consumption, high emission industries and encourage the cleaner production projects which is beneficial to reduce energy consumption and carbon emissions.

\section{ACKNOWLEDGEMENTS}

Soft Science of Beijing Science and Technology Commission (Z131109001613006);

Beijing Social Science Fund (14JGB036)

Humanities and Social Science Fund of Beijing University of Technology (X5104001201301);

Interdisciplinary Beijing Municipal Key

Discipline, "Resources, Environment and Recycling Economy" Project (033000541214001)

The twelfth Science and Technology Fund of Beijing University of Technology (yjk-2013-10470).

\section{REFERENCES}

[1] SU Xuechuan. The Evolution of $t$ he Western Theory of World City and Its Enlightenment to Beijing. Journal of Central University of Finance\&Economics, 2007(2):68-71

[2] Industrialization white paper: the report of the development of the industrialization in China (19952010). Social Sciences Academic Press

[3] Institute of industrial economics of cases. Readjustment and upgrading of industry structure in the 12th Five-Year. China Industrial Economics. 2010(1): 5-23

[4] SONG Deyong \& LU Zhongbao. The Factor Decomposition and Periodic Fluctuations of Carbon Emission in China. China Population Resources and Environment. 2009, 19(3): 18-24.

[5] http://www.bjstats.gov.cn. [EB/OL]

[6] ZHONG Guihong \& WU Yufei. Emphasis and Countermeasures of Developing Low Carbon Economy in Beijing. Ecological Economy. 2011(3):59-63.

[7] ZHANG Wang \& ZHOU Yuemin. The Comparison Research on Situation of Low Carbon Development between Beijing and Major World Cities. World Regional Studies. 2012(4): 143-152

[8] The Twelfth Five-Year Plan for Beijing Saving Energy and Reducing Consumption, and Plan to Address Climate Change.

http://www.bjpc.gov.cn/fzgh_1/guihua/12_5/12_5_qx/. [EB/OL]

[9] Beijing 2013-2017 Clean Air Action Plan http://www.bj.xinhuanet.com/bjyw/201309/13/c_117351459.htm. [EB/OL] 